Check for updates

Cite this: RSC Adv., 2017, 7, 20186

\title{
The analysis of hot spots in large scale fluidized bed reactors
}

\begin{abstract}
Zhao Jia, Chenxi Zhang, Dali Cai, (D) Elena Blair, Weizhong Qian and Fei Wei (D)*
The influence of gas velocity and bed diameter on temperature and hot spot profile in gas-solid fluidized beds is studied based on a 2D pseudo homogeneous phase model. A dimensionless number, the fluidized Prater number $\beta_{\mathrm{f}}$, is introduced into fluidized bed reactors to estimate the temperature gradient and hot spot profile based on various operating parameters and a quantitative relationship is established. Contrary to fixed beds, in fluidized beds, with low gas velocity and small bed diameter, there tend to be large temperature gradients and hot spots. With the increase of gas velocity in the turbulent regime and decrease in the bed diameter, $\beta_{f}$, the hot spot gradually disappears and the temperature profile tends to be more uniform. The hot spot in highly exothermic reactions in fluidized beds can be effectively minimized by increasing gas velocity in the turbulent regime and enlarging the bed diameter. An operating map for the industrial hydrogenation of nitrobenzene reaction is provided to estimate the possible axial temperature gradient from operating parameters. This method can be applied to other similar reactions for selecting operating parameters and methods to eliminate hot spots and produce a uniform temperature gradient.
\end{abstract}

Received 5th December 2016

Accepted 1st April 2017

DOI: 10.1039/c6ra27750k

rsc.li/rsc-advances for methanol synthesis and hydrogenation of nitrobenzene in fluidized beds and found that fluidized beds had hot spots in these highly exothermic reactions. Kaneko ${ }^{17}$ produced a simulation of hot spots in a fluidized bed for polyolefin with bed diameter of $0.154 \mathrm{~m}$, and studied the influence of inlet gas uniformity on hot spots. These researchers all observed the hot spots phenomenon in fluidized beds, but were still in lack of indepth studies on the influence of gas velocity and bed diameter.

Contrary to fixed beds, we also observed that, in fluidized beds, hot spot appears when the bed diameter is small and the gas velocity is low. By increasing the bed diameter and gas velocity in turbulent regime, the hot spot disappears. Same phenomenon have been found in fluidized beds by other researchers. Rao and Reddy $^{12}$ observed this phenomenon in the combustion of rice husk in a fluidized bed with bed diameter of $0.15 \mathrm{~m}$. Song ${ }^{15}$ observed this phenomenon when heated sand and cool air mixing in a fluidized bed with bed diameter of $0.203 \mathrm{~m}$. But these studies were in small scale fluidized beds thus their results were difficult to be applied to industrial fluidized beds. Wei Xiaobo ${ }^{18}$ built a $2 \mathrm{D}$ model for the industrial hydrochlorination of acetylene reaction with bed diameter of $1 \mathrm{~m}$ and found the same phenomenon, but lacked further analysis. Artlich et al. ${ }^{19}$ built a 2D model for coal combustion in a pilot-scale fluidized bed with bed diameter of 1.6 $\mathrm{m}$ to study the hot spot, but they assumed that the solids dispersion coefficient was constant when changing bed diameter, which didn't match reality.

The phenomenon indicates that the effect of gas velocity and bed diameter on heat transfer is extremely important. In fixed beds, a Prater number $\beta$ is widely used to estimate temperature 
gradients and hot spots by the operating parameters. ${ }^{20,21}$ But in fluidized beds, although researchers have paid much attention to this problem, their results are insufficient to reach a general conclusion. Behjat ${ }^{22}$ and Yiannoulakis et al. ${ }^{23}$ found that the higher superficial velocity had a positive effect on the heat transfer coefficient, while Scott, ${ }^{24} \mathrm{Zhou}^{25}$ and Li et al. ${ }^{13}$ found that increasing the gas velocity did not lead to an increase of the heat transfer coefficient. And for the effect of bed diameter, Matsen $^{26}$ found that larger units gave higher mixing rates, but there is no practicable conclusion for industrial fluidized beds, since most of the experiments are in laboratory scale. With the development of computer computing power and new simulation methods, there were more CFD simulations of pilot scale and industrial scale fluidized beds with bed diameters up to one meter in recent years. ${ }^{27-33}$ However, the essential of transfer and dispersion in gas-solid fluidized bed is the rate of the bubble breakage and coalescence, which is still too difficult to do highresolution CFD simulations in much larger bed diameters due to the computational limitations.

In present work, we build a $2 \mathrm{D}$ pseudo homogeneous phase model to study the hot spot problem in fluidized beds and the effect of gas velocity and bed diameter on temperature distribution profile, and compare it with the large scale industrial data. By analogy to the Prater number $\beta$ in fixed beds, a dimensionless number, the fluidized Prater number $\beta_{\mathrm{f}}$, is introduced to represent the ratio of reaction heat production rate and heat transfer rate. This fluidized Prater number $\beta_{\mathrm{f}}$ accounts for the temperature dependence of dispersion and chemical reaction in fluidized beds, and shows a quantitative relationship with the temperature gradient. Finally, an operating map for industrial reaction of nitrobenzene hydrogenation is provided to estimate the possible axial temperature profile. This method, we believe, will also be useful for other highly exothermic reactions.

\section{Model and numerical simulations}

In order to reach more generalized conclusions on the temperature profile and hot spot problem in highly exothermic reactions, a typical industrial reaction of nitrobenzene hydrogenation is carefully studied. The chemical reaction for the hydrogenation of nitrobenzene is shown in equation. ${ }^{34-36}$

$$
\mathrm{C}_{6} \mathrm{H}_{5} \mathrm{NO}_{2}+3 \mathrm{H}_{2}=\mathrm{C}_{6} \mathrm{H}_{7} \mathrm{~N}+2 \mathrm{H}_{2} \mathrm{O}, \Delta H=-544 \mathrm{~kJ} \mathrm{~mol}^{-1}
$$

There are three units of different capacities in SINOPEC Nanjing Chemical Industries Company. Their operating parameters are in Table 1.

Table 1 Operating parameters of hydrogenation of nitrobenzene units in SINOPEC Nanjing Chemical Industries Company

\begin{tabular}{lll}
\hline Capacity (kt/a) & Diameter $(\mathrm{m})$ & Inlet gas velocity $\left(\mathrm{m} \mathrm{s}^{-1}\right)$ \\
\hline 20 & 2.6 & 0.45 \\
50 & 3.7 & 0.7 \\
100 & 5.2 & 0.7
\end{tabular}

Table 2 The governing equations

Mass transfer equation
$\varepsilon_{\text {dense }} \nabla \cdot\left(-D_{\mathbf{g}} \nabla c\right)+u_{\mathbf{g}} \cdot \nabla c=r$

Heat transfer equation

$\nabla \cdot\left(-k_{\mathrm{s}} \nabla T\right)+\rho_{\mathrm{s}} C_{\mathrm{Ps}} u_{\mathrm{s}} \cdot \nabla T=-\left(Q_{\mathrm{p}}-Q_{\mathrm{c}}\right)$

$u_{\mathrm{s}}=u_{\mathrm{g}} \times\left(1-\varepsilon_{\text {dilute }}\right) /\left(1-\varepsilon_{\text {dense }}\right)$

$k_{\mathrm{s}}=D_{\mathrm{s}} \rho_{\mathrm{s}} C_{\mathrm{Ps}}$

Chemical reaction kinetic

$r=k c_{\mathrm{C}_{6} \mathrm{H}_{5} \mathrm{NO}_{2}}$

$k=89.493 \mathrm{e}^{-\frac{3457}{1.987 T}}$

$Q_{\mathrm{p}}=-r \Delta H$

$Q_{\mathrm{c}}=\alpha_{\mathrm{c}} a\left(T-T_{\mathrm{c}}\right)$

Table 3 Parameters and boundary conditions

\begin{tabular}{lll}
\hline Parameter & Value & Unit \\
\hline Inlet temperature of reactants & 190 & ${ }^{\circ} \mathrm{C}$ \\
Molar ratio of $\mathrm{H}_{2}: \mathrm{C}_{6} \mathrm{H}_{5} \mathrm{NO}_{2}$ & 9 & - \\
Heat transfer coefficient of wall & 0.5 & $\mathrm{~W}\left(\mathrm{~m}^{-2} \mathrm{~K}^{-1}\right)$ \\
Heat transfer coefficient of heat exchanger & 450 & $\mathrm{~W}\left(\mathrm{~m}^{-2} \mathrm{~K}^{-1}\right)$ \\
Specific surface area of heat exchanger & 3 & $\mathrm{~m}^{-1}$ \\
Specific heat capacity of solids & 800 & $\mathrm{~J}\left(\mathrm{~kg}^{-1} \mathrm{~K}^{-1}\right)$ \\
Solids density & 900 & $\mathrm{~kg} \mathrm{~m}^{-3}$ \\
Temperature of cooling water & 50 & ${ }^{\circ} \mathrm{C}$
\end{tabular}

A 2D pseudo homogenous dispersion model is adopted to describe the mass and heat transfer through a fluidized bed reactor. ${ }^{18,26}$ The governing equations are in Table 2 . The parameters and boundary conditions are in Table 3 . The chemical reaction kinetic parameters are from the experimental results published by Murthy et al. ${ }^{35-37}$ The voidage profile data is from the experimental results published by Wang ${ }^{34}$ and Das et $a .^{38}$ The operating parameters are based on the actual running parameters in the factory. The solutions to the reaction have been successfully incorporated with the COMSOL Multiphysics software. The mesh is free triangular mesh and after confirming the grid size independence, the grid number are 33 145, 47 176, 66 290, separately.

(1) The axial symmetry.

(2) The flux inlet boundary condition for the mass transfer equation.

(3) The temperature inlet boundary condition for the heat transfer equation.

(4) The outflow outlet boundary condition for the mass transfer equation.

(5) The outflow outlet boundary condition for the heat transfer equation.

(6) The heat flux wall condition for the heat transfer equation.

\section{Results and discussion}

\section{Temperature profile and hot spot problem}

Fig. 1A shows the spatial temperature profile of the $20 \mathrm{kt} / \mathrm{a}$ unit. Fig. 1B shows the axial temperature profile of the three units 

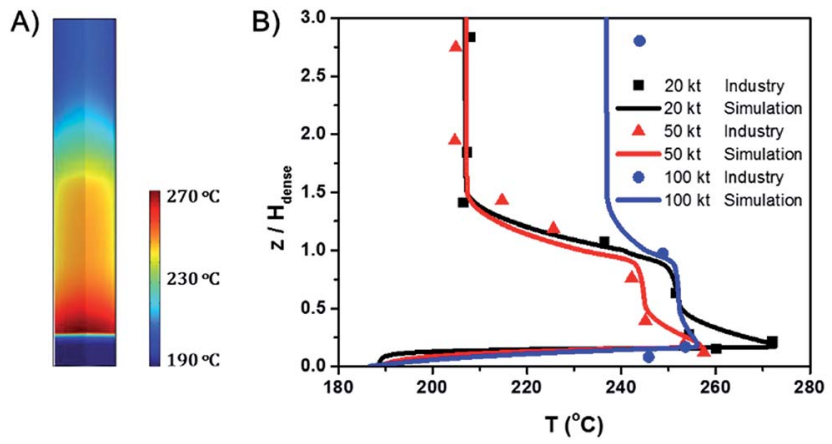

Fig. 1 Spatial and axial temperature profiles.

and compares the simulation results with industrial data. The results derived from the simulation agree well with measured temperature in industrial units. Since the temperature gradient mainly appears in the dense phase region, the height of the dense phase, $H_{\text {dense }}$, is used as a reference and the vertical coordinate is $z / H_{\text {dense. }}$.

Both of the axial and radial temperature profiles are nonuniform, especially in the dense phase region. In the axial profile, temperature reaches the peak near the gas distributor, decreases rapidly with the increase of height and finally reaches a stable value in the dilute phase region. The largest axial temperature gradient reaches $70{ }^{\circ} \mathrm{C}$. A hot spot appears in the middle of the bed just above the gas distributor. As mentioned in the introduction, for highly exothermic reactions, significant temperature gradients and hot spots also appear even in fluidized bed reactors.

Fig. 1B also shows that with the increase of gas velocity and bed diameter, the overall temperature decreases, the maximum temperature of the hot spots decreases and the axial temperature profiles tend to be more uniform.

\section{The fluidized Prater number $\beta_{\mathrm{f}}$}

The generation of the temperature gradient and hot spot is the result of a competition between two mechanisms: reaction heat production rate and heat transfer rate. The thermal energy generation parameter $\beta$, also known as the Prater number, is widely used in fixed beds to estimate temperature gradients and hot spots. The expression in fixed beds is

$$
\beta=\frac{\text { mass dispersion } c(-\Delta H)}{\text { heat dispersion } T}=\frac{D_{\mathrm{A}} c(-\Delta H)}{T k_{\text {effective }}}
$$

The Prater number accounts for the temperature dependence of dispersion and chemical reaction in fixed beds. Usually $\beta=1$ is taken as a critical point above which temperature gradient becomes large. But in fluidized beds, there is no such dimensionless number since the transfer in fluidized bed is much more complicated.

By analogy with fixed beds, the fluidized Prater number $\beta_{\mathrm{f}}$ is introduced into fluidized beds. The fluidized Prater number $\beta_{\mathrm{f}}$ takes both convection term and dispersion term into account. For a gas-solid catalytic reaction, the mass convection and dispersion are mainly relied on gas, since gas is the reactant. The heat convection and dispersion are related to solids, since the specific heat of solids is much larger than that of the gas. The expression for $\beta_{\mathrm{f}}$ in fluidized beds is

$$
\beta_{\mathrm{f}}=\frac{\text { mass transfer } c(-\Delta H)}{\text { heat transfer } T}=\frac{\left(u_{\mathrm{g}} H_{\text {dense }}+\varepsilon_{\text {dense }} D_{\mathrm{g}}\right) c(-\Delta H)}{T \rho_{\mathrm{s}} C_{\mathrm{Ps}}\left(u_{\mathrm{s}} H_{\text {dense }}+D_{\mathrm{s}}\right)}
$$

The fluidized Prater number $\beta_{\mathrm{f}}$ is used to estimate temperature gradients in fluidized beds. When $\beta_{\mathrm{f}}$ increases, the reaction heat rate increases faster than the heat transfer rate and the reaction heat couldn't be transferred efficiently, resulting in heat accumulation, large temperature gradient and even hot spots. When $\beta_{\mathrm{f}}$ decreases, the heat transfer rate increases faster than the reaction heat rate and the reaction heat can be transferred efficiently, resulting in small temperature gradient. So like the Prater number $\beta$ in fixed beds, the fluidized Prater number $\beta_{\mathrm{f}}$ is a convenient criterion indicating large temperature gradient in fluidized beds. Fig. 2 shows the temperature gradient versus $\beta_{\mathrm{f}}$ for the previously mentioned reaction units. With the increase of $\beta_{\mathrm{f}}$, the temperature gradient increases, validating the role of $\beta_{\mathrm{f}}$.

\section{Influence of gas velocity and bed diameter on the fluidized Prater number $\beta_{\mathrm{f}}$}

For a specified reaction, except operating parameters, the most important parameters of $\beta_{\mathrm{f}}$ is the dispersion coefficients of solids and gas. Fig. 3A and B, shows the dispersion coefficients of solids and gas versus gas velocity. ${ }^{1,39-50}$ The last three data points $(20 \mathrm{kt}, 50 \mathrm{kt}, 100 \mathrm{kt})$ are derived from the investigated simulations and are close to Du' $\mathrm{s}^{45}$ experimental results. So the simulated results are reliable in bubbling and turbulent regimes. Results from different researchers fluctuate within a certain range since their experimental conditions are not the same, especially the bed diameter. However, they all have

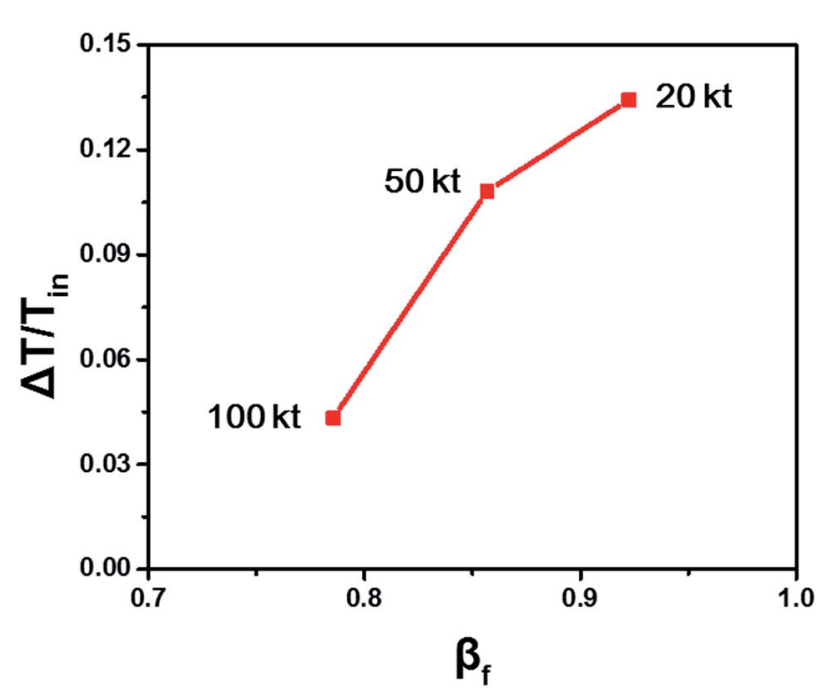

Fig. 2 Temperature gradient versus $\beta_{\mathrm{f}}$. 

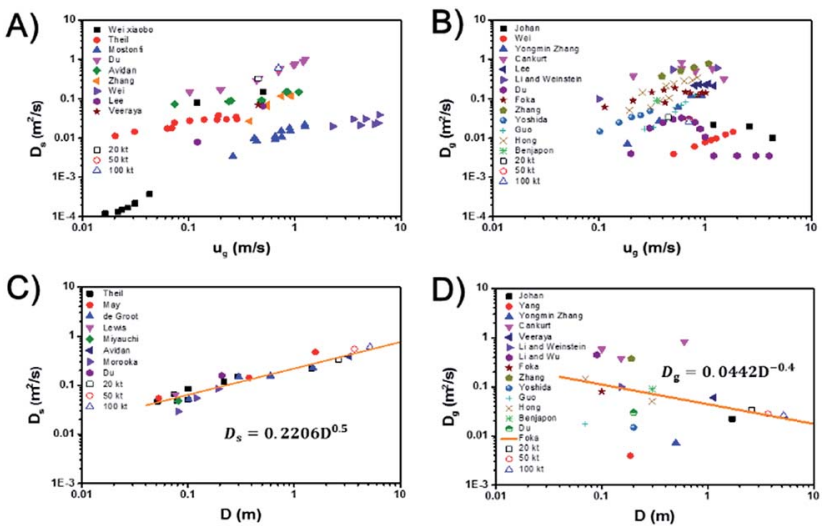

Fig. 3 Solids and gas dispersion coefficients versus gas velocity and bed diameter.

similar trends with increase of gas velocity. For the solids dispersion coefficient, it increases with gas velocity at turbulent regime, and part of the resulting data even shows a non-linear increase ${ }^{45,48,50,51}$ While, with the further increase of gas velocity from turbulent regime to fast fluidization regime, the solids dispersion coefficient decreases suddenly to a very small value due to the phase separation and core-annular flow structure formed in the fast fluidization regime. For the gas dispersion coefficient, it increases with gas velocity at bubbling regime, then gradually decreases in the turbulent regime and finally decreases to a very small value in the fast fluidization regime.

Fig. 3C and D show the solids and gas dispersion coefficients versus bed diameter. The solids and gas dispersion coefficients have an adverse relationship with the increase of bed diameter. For the solids dispersion coefficient, it increases with bed diameter which means a larger fluidized bed has a higher solids mixing ability and can be described by

$$
D_{\mathrm{s}}=0.2206 D^{0.5}
$$

However, the gas dispersion coefficient decreases with bed diameter which means a larger fluidized bed has a lower gas mixing ability, and can be described by

$$
D_{\mathrm{g}}=0.0442 D^{-0.4}
$$

Du's ${ }^{45}$ data of solids and gas dispersion coefficients at different gas velocities are used to calculate the $\beta_{\mathrm{f}}$ to study the influence of gas velocity. The relationship of solids and gas dispersion coefficients at different bed diameters, eqn (12) and (13), are used to calculate $\beta_{\mathrm{f}}$ to study the influence of bed diameter.

Fig. 4A shows the influence of gas velocity on $\beta_{\mathrm{f}}$. With the increase of gas velocity in the bubbling and turbulent regime, $\beta_{\mathrm{f}}$ decreases gradually, which means the temperature gradient would decrease at the same time. But with the further increase of the gas velocity from the turbulent regime to the fast fluidization regime, $\beta_{\mathrm{f}}$ jumps to a very large value, resulting in larger temperature gradient.

Thus, increasing gas velocity in the turbulent regime can decrease $\beta_{\mathrm{f}}$ effectively and avoid the formation of hot spots in
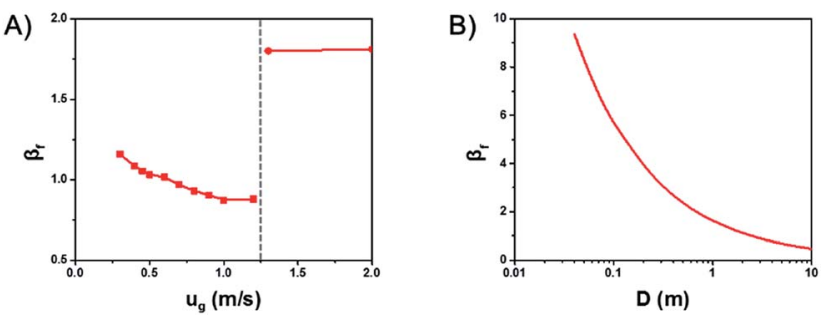

Fig. 4 Influence of gas velocity and bed diameter on $\beta_{f}$.

gas-solid fluidized beds. However, in practice, there lays an upper limit for the gas velocity, for the reason that $\beta_{\mathrm{f}}$ goes up again into the fast fluidization regime. This significantly reduces the heat transfer rate and causes the temperature increase.

The above discussion brings one important issue for real operation of highly exothermic gas-solids fluidized bed reactors to light. When the reactor has a hot spot, decreased gas velocity may cause an increase in hot spot temperature in the fluidized bed, instead of the expected decrease with the decrease load of reaction capacity. The reason is due to the heat transfer ability decreasing more than the mass transfer, with the decreasing gas velocity. This is a dangerous operation zone, for both real case industrial operation and reactor control. Our simulation and experimental data both show this zone exists.

Fig. 4B shows the influence of the scale of the bed diameter on $\beta_{\mathrm{f}}$. With the increase of bed diameter, $\beta_{\mathrm{f}}$ decreases, but the rate of decreasing slows down gradually. Which means an increased bed diameter in gas-solid fluidized beds can decrease the temperature gradient and avoid the generation of hot spot, especially at small and medium bed diameters.

The simulation results and the comparison with industrial data highlight a very important rule for a high exothermic reaction in a fluidized bed reactor scale up, there exists a diameter size for a fluidized bed, for both small and medium diameter, where there exists hot spot. When the reactor diameter increase to even larger, the hot spot disappears, due to the heat transfer ability increasing and the mass transfer ability decreasing. For the scale up of the fluidized bed reactor, checking for the hot spot is very important, and in many cases, scale down may also have a hot spot.

A series of simulations with different gas velocities and bed diameters were conducted in order to verify the rule. The axial temperature profiles at different gas velocities with a bed diameter of $2.6 \mathrm{~m}$ are shown in Fig. 5A. With a gas velocity
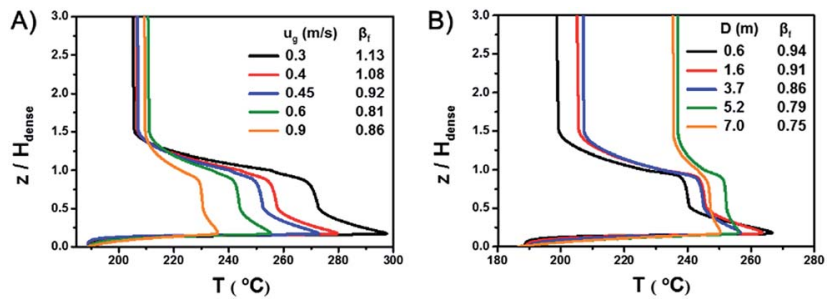

Fig. 5 Axial temperature profile versus gas velocity and bed diameter. 


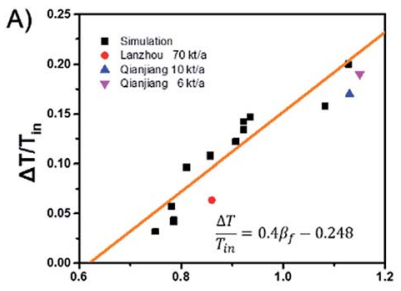

$\beta_{1}$

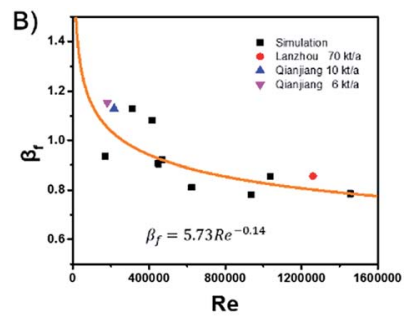

$\mathrm{Re}$
Fig. 6 Operating map for hydrogenation of nitrobenzene reaction.

increases from $0.3 \mathrm{~m} \mathrm{~s}^{-1}$ to $0.9 \mathrm{~m} \mathrm{~s}^{-1}$ and $\beta_{\mathrm{f}}$ decreases from 1.13 to 0.86 , the overall temperature decreases, the maximum temperature of the hot spots decreases and the axial temperature profiles tend to be more uniform. The axial temperature profiles of different bed diameters with a gas velocity of $0.7 \mathrm{~m}$ $\mathrm{s}^{-1}$ are shown in Fig. 5B. With a bed diameter increases from $0.3 \mathrm{~m}$ to $7 \mathrm{~m}$ and $\beta_{\mathrm{f}}$ decreases from 0.94 to 0.75 , the maximum temperature of the hot spots decreases and the axial temperature profiles tend to be more uniform as well.

\section{Operating map for industrial hydrogenation of nitrobenzene reaction}

For the design and operation of a highly exothermic reaction in a fluidized bed reactor, an operation map for this type of system is important. Fig. 6 shows the operating map for the industrial hydrogenation of nitrobenzene reaction. Fig. 6A shows the temperature gradient versus the $\beta_{\mathrm{f}}$. The curve-fitting equation is

$$
\frac{\Delta T}{T_{\text {in }}}=0.4 \beta_{\mathrm{f}}-0.248
$$

This equation gives a convenient criterion for temperature gradient. According to the equation, when $\beta_{\mathrm{f}}=1$, then $\Delta T / T_{\mathrm{in}}=$ 0.152 , which means when the inlet temperature is $200^{\circ} \mathrm{C}, 473 \mathrm{~K}$, then the temperature gradient is $72{ }^{\circ} \mathrm{C}$. And if the temperature gradient must be controlled in $30{ }^{\circ} \mathrm{C}$, then $\beta_{\mathrm{f}}<0.77$.

Fig. 6B shows $\beta_{\mathrm{f}}$ versus the Reynolds number, Re. The curvefitting equation is

$$
\beta_{\mathrm{f}}=5.73 \mathrm{Re}^{-0.14}
$$

The black points and the fitted curve are calculated from the mentioned simulations. The other three industrial data points are fitted well with the curve. ${ }^{14}$ Fig. 6 can be used to calculate the possible axial temperature gradient for the industrial hydrogenation of nitrobenzene reaction. This method and the fluidized Prater number $\beta_{\mathrm{f}}$ can be promoted to other similar reactions.

\section{Conclusions}

In this investigation, a 2D pseudo homogeneous phase model was built to simulate the highly exothermic hydrogenation of nitrobenzene reaction in gas-solid fluidized reactors and then compared with the industrial temperature profiles. Simulation results and industrial data showed that for highly exothermic reactions, there could be hot spots even in fluidized beds, resulting in the deterioration of the catalyst, low conversion of the reactant, low yield of the desirable product and even security risks.

Furthermore, the fluidized Prater number $\beta_{\mathrm{f}}$ is introduced for theoretical analysis and the quantitative calculation of the temperature gradient. It is a criteria on comparing reaction heat production rate and heat transfer rate.

The cause of the hot spot and the effect of gas velocity and bed diameter have been analysed via $\beta_{\mathrm{f}}$. Contrary to fixed beds, in fluidized beds, with low gas velocity, there tends to be a large temperature gradient and hot spot. While with the increase of gas velocity in turbulent regime, $\beta_{\mathrm{f}}$ decreases, the overall temperature decreases, the hot spot gradually disappears and the temperature profile tends to be more uniform. Therefore, the conventional idea to copy the operation from a fixed bed reactor to a fluidized bed reactor when the hot spot appears, which would be to decrease the gas velocity in order to decrease load, is incorrect and even dangerous. But the gas velocity cannot be too high into fast fluidization regime, in case that $\beta_{\mathrm{f}}$ increases again and the temperature increases at the same time.

For the bed diameter, with small diameter, there tends to be a large temperature gradient and hot spot. While with the increase of bed diameter, $\beta_{\mathrm{f}}$ decreases, the hot spot gradually disappears and the temperature profile tends to be more uniform. In addition, it is much easier to design a fluidized bed with large bed diameter to be operated in high gas velocity in turbulent regime, which is more effective to eliminate the hot spot problem.

An operating map for the industrial hydrogenation of nitrobenzene reaction is provided to estimate the possible axial temperature gradient by operating parameters, and this method can be utilized for other similar reactions.

\begin{tabular}{|c|c|}
\hline$a$ & Specific surface area of the heat exchanger, $\mathrm{m}^{-1}$ \\
\hline$c$ & Concentration of gas, $\mathrm{mol} \mathrm{m}^{-3}$ \\
\hline$c_{\mathrm{C}_{6} \mathrm{H}_{5} \mathrm{NO}_{2}}$ & Concentration of $\mathrm{C}_{6} \mathrm{H}_{5} \mathrm{NO}_{2}, \mathrm{~mol} \mathrm{~m}^{-3}$ \\
\hline$C_{\mathrm{Ps}}$ & Specific heat of solids, $\mathrm{J}\left(\mathrm{kg}^{-1} \mathrm{~K}^{-1}\right)$ \\
\hline$D_{\mathrm{A}}$ & Effective diffusivity of reactant $\mathrm{A}$ in fixed beds, $\mathrm{m}^{2} \mathrm{~s}^{-1}$ \\
\hline$D_{\mathrm{s}}$ & Solids dispersion coefficient, $\mathrm{m}^{2} \mathrm{~s}^{-1}$ \\
\hline$D_{\mathrm{g}}$ & Gas dispersion coefficient, $\mathrm{m}^{2} \mathrm{~s}^{-1}$ \\
\hline$H_{\text {dense }}$ & Height of dense phase region, $\mathrm{m}$ \\
\hline$k$ & Chemical reaction rate coefficient, $\mathrm{s}^{-1}$ \\
\hline$k_{\text {effective }}$ & $\begin{array}{l}\text { Effective thermal conductivity of a porous catalyst in } \\
\text { fixed beds, } \mathrm{J}\left(\mathrm{m}^{-1} \mathrm{~s}^{-1} \mathrm{~K}^{-1}\right)\end{array}$ \\
\hline$k_{\mathrm{s}}$ & $\begin{array}{l}\text { Thermal dispersion coefficient of solids, } \mathrm{J}_{\left(\mathrm{m}^{-1} \mathrm{~s}^{-1}\right.} \\
\left.\mathrm{K}^{-1}\right)\end{array}$ \\
\hline$Q_{\mathrm{c}}$ & Heat removal rate of cooling water, $\mathrm{J}_{\left(\mathrm{m}^{-3} \mathrm{~s}^{-1}\right)}$ \\
\hline$Q_{\mathrm{p}}$ & Reaction heat production rate, $\mathrm{J}\left(\mathrm{m}^{-3} \mathrm{~s}^{-1}\right)$ \\
\hline$r$ & Chemical reaction rate, $\mathrm{mol}\left(\mathrm{m}^{-3} \mathrm{~s}^{-1}\right)$ \\
\hline Re & The Reynolds number, dimensionless \\
\hline$T$ & Temperature, $\mathrm{K}$ \\
\hline$T_{\mathrm{c}}$ & Temperature of cooling water, $\mathrm{K}$ \\
\hline$T_{\text {in }}$ & Temperature of inlet gas, $\mathrm{K}$ \\
\hline$u_{\mathrm{s}}$ & Superficial velocity of solids, $\mathrm{m} \mathrm{s}^{-1}$ \\
\hline$u_{\mathrm{g}}$ & Inlet velocity of gas, $\mathrm{m} \mathrm{s}^{-1}$ \\
\hline
\end{tabular}

\section{Nomenclature}


$z \quad$ Axial height, $\mathrm{m}$

$\alpha_{\mathrm{s}} \quad$ Heat transfer coefficient of heat exchanger, $\mathrm{W}\left(\mathrm{m}^{-2}\right.$ $\mathrm{K}^{-1}$ )

$\beta \quad$ The Prater number in fixed beds, dimensionless

$\beta_{\mathrm{f}} \quad$ The fluidized Prater number, dimensionless

$\rho_{\mathrm{s}} \quad$ Apparent density of solids, $\mathrm{kg} \mathrm{m}^{-3}$

$\varepsilon_{\text {dilute }} \quad$ Voidage in dilute phase region, dimensionless

$\varepsilon_{\text {dense }} \quad$ Voidage in dense phase region, dimensionless

$\Delta H \quad$ Heat of chemical reaction, $\mathrm{J} \mathrm{mol}^{-1}$

$\Delta T \quad$ Temperature gradient, $\mathrm{K}$

\section{Acknowledgements}

This work was supported by the National Basic Research Program of China (973 Program, 2011CB932602), the National Natural Science Foundation of China (No.20141301065 and 21306103) and Tsinghua National Laboratory for Information Science and Technology.

\section{Notes and references}

1 H. T. Bi, N. Ellis, I. A. Abba and J. R. Grace, Ind. Eng. Chem. Fundam., 2000, 55, 4789.

2 J. R. Grace, Powder Technol., 2000, 113, 242.

3 A. Stefanova, H. T. Bi, C. J. Lim and J. R. Grace, Int. J. Heat Mass Transfer, 2008, 51, 2020.

4 J. Wang, Particuology, 2010, 8, 176.

5 A. Stefanova, Heat Transfer Near The Transition to Turbulent Fluidization, The University of British Columbia, 2009.

6 V. V. Ranade, Computational Flow Modeling For Chemical Reactor Engineering, 2002.

7 M. Rüdisüli, T. J. Schildhauer, S. M. A. Biollaz and J. R. van Ommen, Powder Technol., 2012, 217, 21.

8 S. Ge, L. Xinchun, Q. Weizhong, C. Wei, S. Congyu, S. Yongjun and Y. Xiaoqiu, Energy Procedia, 2012, 29, 552.

9 J. Werther and E.-U. Hartge, Ind. Eng. Chem. Res., 2004, 43, 5593.

10 S. Khajeh, Z. Arab Aboosadi and B. Honarvar, J. Nat. Gas Sci. Eng., 2014, 19, 152.

11 M. R. Rahimpour and M. Bayat, Int. J. Hydrogen Energy, 2011, 36, 6616.

12 K. V. N. S. Rao and G. V. Reddy, Combust. Sci. Technol., 2007, 179, 1589.

13 Z. Li, M. van Sint Annaland, J. A. M. Kuipers and N. G. Deen, Chem. Eng. Sci., 2016, 140, 279.

14 W.-z. Qian, C.-h. Ke, X.-m. Fang and G. X. Fei Wei, Mod. Chem. Ind., 2005, 25, 49-53.

15 J. C. Song, N. Yutani and L. T. Fan, Ind. Eng. Chem. Fundam., 1984, 23, 170-174.

16 E. Pourazadi, R. Vakili, D. Iranshahi, A. Jahanmiri and M. R. Rahimpour, Can. J. Chem. Eng., 2013, 91, 54.

17 Y. Kaneko, T. Shiojima and M. Horio, Chem. Eng. Sci., 1999, 54(24), 5809-5821.

18 W. Xiaobo, Study of Muti-Stage Fluidized bed Reactor for Producing Vinyl Chloride from Acetylene and Non-mercury Catalyst, Tsinghua University, 2008.
19 S. Artlich, E.-U. Hartge and J. Werther, Ind. Eng. Chem. Res., 1998, 37, 782.

20 P. B. Weisz and J. S. Hicks, Chem. Eng. Sci., 1962, 17, 265.

21 L. A. Belfiore, Can. J. Chem. Eng., 2007, 85, 268.

22 Y. Behjat, S. Shahhosseini and S. H. Hashemabadi, Int. Commun. Heat Mass Transfer, 2008, 35, 357.

23 H. Yiannoulakis, A. Yiagopoulos and C. Kiparissides, Chem. Eng. Sci., 2001, 56, 917.

24 S. A. Scott, J. F. Davidson, J. S. Dennis and A. N. Hayhurst, Ind. Eng. Chem. Res., 2004, 43, 5632.

25 Z. Y. Zhou, A. B. Yu and P. Zulli, AIChE J., 2009, 55, 868.

26 J. M. Matsen, Powder Technol., 1996, 88, 237.

27 Y. Che, Z. Tian, Z. Liu, R. Zhang, Y. Gao, E. Zou, S. Wang and B. Liu, Powder Technol., 2015, 286, 107.

28 Y.-Q. Zhuang, X.-M. Chen, Z.-H. Luo and J. Xiao, Comput. Chem. Eng., 2014, 60, 1.

29 H. Liu, R. J. Cattolica and R. Seiser, Int. J. Hydrogen Energy, 2016, 41, 11974.

30 H. Pan, X.-Z. Chen, X.-F. Liang, L.-T. Zhu and Z.-H. Luo, Powder Technol., 2016, 299, 235.

31 Y. Che, Z. Tian, Z. Liu, R. Zhang, Y. Gao, E. Zou, S. Wang and B. Liu, Powder Technol., 2015, 278, 94.

32 S. Schneiderbauer, S. Puttinger, S. Pirker, P. Aguayo and V. Kanellopoulos, Chem. Eng. J., 2015, 264, 99.

33 L.-T. Zhu, L. Xie, J. Xiao and Z.-H. Luo, Chem. Eng. Sci., 2016, 143, 369.

34 Z. Wang, Gas mixing and hydrodynamic behaviors in a turbulent fluidized bed, Tsinghua University, 1997.

35 M. Jinsheng, Chem. React. Eng. Technol., 1988, 4, 64.

36 W. Zhi-guo, J. Shan and W. Fei, Chem. React. Eng. Technol., 2001, 17, 278-281.

37 M. S. Murthy, Chem. Age India, 1963, 14, 653.

38 M. Das, A. Bandyopadhyay, B. C. Meikap and R. K. Saha, Chem. Eng. J., 2008, 145, 249.

39 M. Foka, J. Chaouki, C. Guy and D. Klvana, Chem. Eng. Sci., 1996, 51, 713.

40 J. Liu, J. R. Grace, H. T. Bi, H. Morikawa and J. Zhu, Chem. Eng. Sci., 1999, 54(22), 5441-5449.

41 H. I. Cho, C.-H. Chung, G. Y. Han, G. R. Ahn and J. S. Kong, Korean J. Chem. Eng., 2000, 17(3), 292.

42 J. Sterneus, F. Johnsson and B. Leckner, Powder Technol., 2002, 126, 28.

43 Y. Yanhui, J. Xinli, W. Fei and J. Yong, Chin. J. Chem. Eng., 2001, 9, 291.

44 R. Krishna and J. M. v. Baten, Chem. Eng. J., 2001, 82, 247.

45 B. Du, L.-S. Fan, F. Wei and W. Warsito, AIChE J., 2002, 48, 1896.

46 R. W. Breault, Powder Technol., 2006, 163, 9.

47 V. Jiradilok, D. Gidaspow and R. W. Breault, Chem. Eng. Sci., 2007, 62, 3397.

48 Y. Zhang, C. Lu and M. Shi, Chem. Eng. Res. Des., 2009, 87, 1400.

49 B. Chalermsinsuwan, D. Gidaspow and P. Piumsomboon, Chem. Eng. J., 2011, 171, 301.

50 A. Avidan and J. Yerushalmi, AIChE J., 1985, 31, 835.

51 D. Gidaspow, J. Jung and R. K. Singh, Powder Technol., 2004, 148, 123. 